\title{
Introductory editorial thematic issue: geochemistry of surface processes (III RAGSU)
}

\author{
Daniel E. Martínez ${ }^{1,2} \cdot$ Karina S.B. Miglioranza $^{1} \cdot$ Héctor E. Massone $^{2}$
}

Received: 5 January 2017/Accepted: 15 January 2017/Published online: 20 January 2017

(C) Springer-Verlag Berlin Heidelberg 2017

Geochemistry, as a discipline linking geology and chemistry, was from the beginning focused on the study of the composition of rocks and their formation. The discipline developed the same way in Argentina and similarly in the rest of Latin America. One of the papers included particularly in this Thematic Issue is related to the history of geochemistry, which constituted a starting point and moreover a reference for present day investigations.

Geological materials, formed at high pressures and temperatures, outcrop at the surface, forming the Earth's landscape. Upon being exposed to low pressure and temperature conditions, they interact with the atmosphere, the hydrosphere and the human race. Thus, minerals become unstable; chemical elements take ionic forms and are able to move in water and air; new substances are created by man; and other natural products are strongly concentrated in some sites. The study of geochemical processes of the Earth's surface, as a new area of geochemistry where interdisciplinary work is prevalent, is focused on chemical reactions which attempt to attain a steady state and, moreover, on geological movements of materials which alter that chemical equilibrium.

This article is part of a Topical Collection in Environmental Earth Sciences on "3RAGSU" guest edited by Daniel Emilio Martinez.

Daniel E. Martínez

demarti@mdp.edu.ar

1 Instituto de Investigaciones Marinas y Costeras (CONICETU.N. de Mar del Plata), 7600 Mar del Plata, Buenos Aires, Argentina

2 Instituto de Geología de Costas y del Cuaternario (U.N. de Mar del Plata-CIC), 7600 Mar del Plata, Buenos Aires, Argentina
Based on this framework driven by the enthusiastic pioneer Dr. Pedro Depetris, and the need for a new space to discuss geochemistry of surface processes, the concept was finally crystallized in the Argentinean Meeting of Geochemistry of the Surface, called RAGSU from the acronym of its Spanish name "Reunion Argentina de Geoquímica de la Superficie". The first RAGSU was held in Córdoba, Argentina in 2008. A Thematic Issue of Environmental Earth Sciences (EES) was published based on selected papers from the meeting.

In later editions, RAGSU was consolidated as an intensive meeting among specialists which highlighted experiences and exchanges between colleagues. It is not a large conference but rather a specialized smaller meeting bringing together many younger researchers doing novel work and nationally known researchers from different disciplines. RAGSU has become known for its convergence of colleagues presenting the latest results and advances in their respective fields and discussing the detailed processes that affect the portion of the Earth where man is living.

The third edition of RAGSU was held in Mar del Plata, Argentina, in December 2014. More than 150 presentations were made in oral and poster sessions. A smaller number of articles were selected to be published in this Thematic Issue after being expanded based on discussions during the conference and subsequent additional research. Topics included a complex but consistent aggregate of studies focused on soils, atmosphere, coastal oceanic areas, rivers, lakes and aquifers, metals, organic compounds, isotopes and indicators under the overall concept of the geochemistry of the surface. Furthermore, different regions of Argentina and Latin America were considered and are reflected in papers of this Thematic Issue. The particular environmental conditions of the Humid Pampa, 
the Andes, the Patagonian plateau, the large rivers, the northwestern deserts and the central mountains are the scenarios of and simultaneously the conditioning environment for a wide variety of geochemical processes and related impacts.

The geochemistry of surface is growing as a discipline in Argentina, Latin America and around the world. Research groups continue to increase their capabilities and the products therefrom, making possible the completion of this Thematic Issue from III RAGSU in the Journal Environmental Earth Sciences (EES). It is a pleasure as Guest Editors to have the opportunity to publish this Thematic Issue. The scope of EES corresponds well with the themes of RAGSU, and this continued collaboration is planned to continue with another Thematic Issue from IV RAGSU in the future. The important support of Environmental Earth Sciences Journal to the RAGSU meetings is acknowledged and appreciated. 